\title{
MORBIDADE DECLARADA E CONDIÇÕES DE TRABALHO o caso dos motoristas de São Paulo e Belo Horizonte
}

\author{
Leticia B. C osta \\ Mitti Ayako Hara Koyama \\ Elaine Garcia Minuci \\ Frida Marina Fischer
}

\begin{abstract}
Resumo: Neste artigo se apresentam os principais resultados de levantamentos feitos em São Paulo e Belo Horizonte sobre as condições de trabalho e de saúde dos motoristas do transporte de passageiros. Constataram-se condições de trabalho bastante desfavoráveis e estabeleceram-se associações estatísticas entre essas condições e sérios sintomas de morbidade declarados pelos motoristas. Sugere-se a necessidade de políticas públicas para o setor.
\end{abstract}

Palavras-chave: condições de trabalho; sintomas declarados; motoristas.

\begin{abstract}
This article presents the main results of research carried out in São Paulo and Belo Horizonte into the working conditions and health of mass transit drivers. Rather unfavorable conditions were observed and statistical links were established between these conditions and symptoms of grave morbidity reported by the drivers. Some public policies for this sector are recommended.

Key words: working conditions; reported symptoms; drivers.
\end{abstract}

$\stackrel{2}{\Omega}$ amplamente conhecido o caráter essencial dos transportes, e transportes de qualidade, não só como infra-estrutura para os processos de produção, mas também como pré-requisito para uma boa qualidade de vida dos cidadãos. Segundo Siqueira (1996:18), “[...] merecem destaque as políticas urbanas para os transportes. Estes possuem elevada essencialidade e responsabilidade social, já que o consumo de vários bens intimamente ligados às condições de vida e aos direitos dos cidadãos depende dos transportes. Habitação, trabalho, saúde, educação e convívio social pressupõem condições de locomoção para sua satisfação. Os transportes interferem na carga total de trabalho, afetando o chamado 'tempo de indisponibilidade', ou seja, o tempo que o trabalhador gasta para se locomover da residência para o trabalho e vice-versa e que se agrega ao tempo gasto no trabalho propriamente dito. Muitos trabalhadores aceitam más condições de trabalho e de salário para ter trajetos mais curtos e menos 'tempo de indisponibilidade'. Por estas razões, as políticas urbanas para os transportes têm de estar em condições de realçar sua capacidade de integrar-se à melhoria das condições básicas de vida de todas as classes sociais."
A implementação de um sistema de transportes geralmente se assenta no tripé iniciativa privada, como agente provedor dos recursos financeiros e gerenciais; trabalhadores, como mão-de-obra para operação do sistema; e governo, como agente fiscalizador do bom desempenho, tendo em vista, de um lado, os interesses do cidadão e, de outro, as condições de trabalho da mão-de-obra envolvida. Em tal esquema, a figura do motorista é um elemento fundamental. Pesquisas anteriores (Faculdade de Medicina da USP, Fundacentro e Sindicato dos Trabalhadores nos Transportes de São Paulo, 1990) têm demonstrado que, no nosso meio, o motorista está sujeito a um trabalho extenuante, que compromete não só a sua saúde, mas também a segurança de passageiros e pedestres.

Não é por menos que a Fundacentro, entidade ligada ao Ministério do Trabalho e Emprego, se mobilizou para conhecer mais os motoristas de ônibus dos grandes centros brasileiros, com a finalidade de obter subsídios para o planejamento de ações estratégicas que pudessem reduzir os aspectos penosos da profissão e da qualidade de vida desse grupo de trabalhadores. Assim, ela encomendou à Fundação Seade uma pesquisa sobre as condições de saúde e segurança dos motoristas do transporte coleti- 
vo urbano, nas Regiões Metropolitanas de São Paulo e Belo Horizonte.

Atendendo a essa solicitação, foram planejadas e executadas duas pesquisas de campo. Em dezembro de 2000, foram entrevistados, nos terminais das linhas de ônibus, 1.762 motoristas de linhas operadas na Região Metropolitana de São Paulo, integrando uma amostra aleatória que permite expandir os resultados para o conjunto desses trabalhadores, que somam cerca de 22 mil pessoas. Foram realizadas entrevistas por meio de um questionário, cuja aplicação durava aproximadamente 12 minutos, com cada motorista.

Na Região Metropolitana de Belo Horizonte, foram entrevistados, em janeiro de 2002, 984 motoristas das linhas operadas na região. Trata-se também de uma amostra aleatória e representativa do conjunto desses profissionais, que congrega 15 mil pessoas. O questionário usado, muito semelhante ao da pesquisa em São Paulo, levava 18 minutos para ser aplicado.

Nesses levantamentos foram abordados cinco temas: características pessoais dos motoristas e alguma informação sobre sua família; condições de trabalho dos motoristas, incluindo características dos veículos dirigidos por eles; contexto social em que se desenrola o trabalho, considerando também a violência urbana; condições de saúde dos motoristas, segundo os sintomas por eles declarados; e a questão dos acidentes, suas conseqüências e possíveis causas.

Dentro do escopo da pesquisa, nas duas regiões foram realizadas entrevistas qualitativas com empresários do transporte de passageiros, com representantes dos órgãos governamentais que têm jurisdição sobre os serviços, com sindicatos patronais e de trabalhadores. Todos eles abriram suas portas para os pesquisadores do Seade, facilitando também a seleção de amostras representativas de motoristas e autorizando a realização de entrevistas com motoristas e fiscais, nos finais de linha.

Este artigo se fundamenta nos resultados dessa pesquisa e pretende não apenas divulgar alguns dos achados mais importantes, como também testar as possíveis associações existentes entre os principais aspectos das condições de trabalho e hábitos pessoais desses motoristas e os sintomas de morbidade por eles declarados.

$\mathrm{O}$ artigo se articula em várias partes. Discute-se, inicialmente, a validade de inferências sobre a saúde do indivíduo a partir de sintomas referidos por ele mesmo, sem nenhuma comprovação médica. Na seqüência, são traçadas algumas considerações sobre o transporte de passageiros por ônibus nas duas regiões, suas similaridades e diferenças. São apresentadas a seguir as informações sobre as condições de trabalho e saúde dos motoristas, levantadas nas pesquisas de campo. Passa-se então ao ajustamento de modelos estatísticos que permitem testar e quantificar as associações existentes entre sintomas de morbidade, de um lado, e condições de trabalho e hábitos de vida, de outro. Por fim, as conclusões e sugestões julgadas pertinentes.

\section{MORBIDADE DECLARADA NA LITERATURA}

São freqüentes na literatura especializada os estudos empíricos sobre a relação entre a sintomatologia relatada pelos sujeitos e a evolução futura de sua condição de saúde, medida pela incidência da incapacitação física ou da morte nos anos subseqüentes. A idéia que se depreende desses estudos é que o próprio indivíduo tem capacidade para perceber e relatar razoavelmente bem, como se verá logo abaixo, as suas condições de saúde.

Ferraro e Ya-ping Su (2000) analisaram a validade da auto-avaliação da saúde na previsão da incapacitação física nos anos subsequëntes, em comparação com a avaliação médica dos mesmos sujeitos, usando para isso dados da National Health and Nutrition Examination Survey e do Epidemiologic Follow-Up Study, por um período de 15 anos. Foram entrevistados e examinados inicialmente 5.955 brancos e 878 negros, de 25 a 74 anos de idade. O viés introduzido pelas perdas por morte, mudança de endereço ou recusa de participar foi controlado estatisticamente no modelo usado. "Os resultados mostraram que as medidas tanto da morbidade avaliada por médicos como da morbidade referida tinham uma relação estatisticamente significante com o surgimento de incapacidade física dez anos depois do primeiro levantamento, mas a relação mais forte provinha da morbidade referida, especialmente quando consideradas as doenças crônicas não sérias". Além do mais, a relação entre a morbidade avaliada por médicos, com base na Classificação Internacional de Doenças, e a incidência de incapacidade, 15 anos depois, não apresentou significância estatística. Assim, as conclusões se referem especificamente a medidas de saúde tomadas em levantamentos de saúde e podem não ser válidas quando a morbidade é avaliada a partir das fichas clínicas dos pacientes.

Um outro estudo (Benyamini et al., 2000) focaliza as diferenças de gênero na auto-avaliação da saúde e o impacto dessas diferenças na predição da mortalidade. Tal 
pesquisa contou com a participação de 851 idosos. Depois de um período de cinco anos, 830 pessoas da amostra original (497 mulheres e 333 homens) foram localizadas vivas ou mortas, perdendo-se 21 casos. As pessoas que, no início da pesquisa, consideraram sua saúde regular ou má apresentaram uma probabilidade 4,8 vezes maior de morrer do que as que disseram ter saúde muito boa ou excelente. A associação entre saúde regular ou má e mortalidade foi mais fraca para as mulheres do que para os homens. Várias explicações são adiantadas pelos autores, entre elas a relação com a saúde e a doença, que é diferente para homens e mulheres, sendo que estas tendem a levar em conta também as doenças leves, não fatais, que são desconsideradas pelos homens. Outro fator das diferenças pode ser que as mulheres, mais frequientemente que os homens, são "cuidadoras" de um companheiro idoso, deixando-se envolver pelos problemas desse companheiro, com reflexos não fatais sobre sua saúde. Segundo os autores, os resultados obtidos não podem ser generalizados, pois a amostra não era representativa, tendo sido formada por voluntários.

No já clássico livro, As classes sociais e o corpo, Boltanski (1989) estudou as diferenças existentes entre as distintas classes sociais, na França dos anos 60, na postura diante do corpo e das doenças, assim como no acesso ao médico e a explicações médicas sobre saúde e tratamento. Ele mostra como, devido à menor exposição ao médico, as classes subalternas assimilaram mal as categorias médicas de compreensão da doença e, por isso, usam um vocabulário muito mais restrito e têm uma percepção mais limitada da doença. Enquanto as pessoas mais bem situadas são alertadas pelos primeiros sintomas de uma doença, nas classes menos favorecidas a doença tende a ser levada em consideração apenas quando interfere no uso pleno do corpo, normalmente para o trabalho. E então, muitas vezes, a doença já vai avançada. Essas colocações mostram a dificuldade de se compararem auto-avaliações feitas por diferentes grupos sociais.

Estudando especificamente auto-avaliações feitas por trabalhadores, diz Fischer (1990): “A respeito desta forma de coleta de dados pronunciam-se vários autores: ' $O$ conhecimento operário a respeito de seu trabalho e de seu impacto sobre a saúde é, sem dúvida, muito rico, e oferece uma compreensão da problemática em grande medida resgatável unicamente a partir da ótica operária' (Laurell e Noriega, 1989). Estes autores, apontam ainda que entre as vantagens de obter informações a respeito das condições de trabalho e seus efeitos na saúde 'a experiência dos trabalhadores permite alcançar um conhecimento preciso do processo de trabalho, suas cargas, e dimensões distintas do desgaste...'. Similar opinião é compartilhada por Smith, Colligan e Tasto (1979), em trabalho onde avaliam os méritos relativos da aplicação de questionários e outros métodos de coleta de dados: 'um levantamento realizado com questionários ainda que menos objetivo que os registros de saúde e segurança ou um estudo médico, é uma maneira eficiente e rápida de levantar uma quantidade grande e detalhada coleção de dados acerca das consequiências psicológicas, sociais e de saúde do trabalho...' Estes dados geralmente não constam de registros mantidos nas empresas".

\section{O TRANSPORTE DE PASSAGEIROS EM SÃO PAULO E BELO HORIZONTE}

Existem similaridades e diferenças entre as duas metrópoles e seus sistemas de transporte de passageiros por ônibus.

A Região Metropolitana de São Paulo - que agrega 39 municípios - contava, em 2000, com uma população de aproximadamente 20 milhões de pessoas, sendo 10,4 só no $\mathrm{Mu}$ nicípio de São Paulo (censo de 2000). É, reconhecidamente, o centro financeiro e de negócios do país. Não obstante o crescimento de outros pólos industriais, São Paulo mantém sua posição de maior parque industrial da América Latina. Ao mesmo tempo, está conectado a outros pólos, como São José dos Campos, Rio de Janeiro, Baixada Santista, Campinas e interior paulista, Minas Gerais e sul do país.

A Região Metropolitana de Belo Horizonte, com cerca de um quarto da população de São Paulo (4,8 milhões), é um conjunto de 34 municípios, agrupados quase que circularmente em torno do município que lhe dá o nome. Segundo o Censo de 2000, Belo Horizonte é uma das maiores cidades do país, com 2,2 milhões de habitantes. Sua importância econômica, política e social advém tanto de suas próprias atividades, como de sua localização estratégica, pois constitui ligação obrigatória entre várias regiões do país. Para atender a essa vocação, a RMBH é servida por amplo sistema viário, uma vez que $15 \%$ das rodovias federais pavimentadas do país, além de $16 \%$ da malha ferroviária nacional, estão no Estado de Minas Gerais (Cançado et al., 1999:288).

Seus sistemas de transporte de passageiros sobre pneus guardam correspondência com o tamanho relativo das duas regiões. São Paulo contava, por ocasião da pesquisa de campo, com 10.700 ônibus no município e 3.600 na re- 
gião, ao passo que, em Belo Horizonte, os ônibus municipais eram 2.900 e os metropolitanos, cerca de 2.000 .

Percorrendo trajetórias diferentes, nas duas regiões os sistemas são administrados de forma semelhante. Em ambas, o serviço é produzido por empresas privadas, sob jurisdição do poder público: o SPTrans e a EMTU, respectivamente, no município e na metrópole paulista; a BHTrans e o DER/MG, no município e na Região Metropolitana de Belo Horizonte. A BHTrans tem sob sua tutela as operadoras que servem exclusivamente o município de Belo Horizonte, já o DER responde não só pelo sistema nas demais cidades da RMBH que ainda não assumiram responsabilidade pelo seu transporte, mas também por todo o sistema rodoviário do Estado. As poucas empresas que operam em ambos os sistemas são fiscalizadas pelo DER.

Em São Paulo, o transporte coletivo foi instituído primeiro pelo capital estrangeiro (Light \& Power), cujo monopólio foi sendo aos poucos contestado por pequenas transportadoras particulares, depois o poder público assumiu a prestação direta do serviço, instalando para isso, em 1947, a Companhia Municipal de Transportes Coletivos (CMTC). Nos anos 50, registrou-se uma proliferação de empresas de transporte, ao lado da CMTC, que foi passando ao papel de reguladora e sustentadora do mercado, ao mesmo tempo que se encarregava das linhas menos rentáveis, pela ótica da função social do transporte de passageiros (Henry; Zioni, 1999). Com a extinção da CMTC, em 1994, a situação ficou claramente definida: gestor público, operadoras privadas.

Uma característica do mercado de serviços de ônibus de passageiros, em São Paulo, é o alto nível de concentração de capital. Grande parte desse capital não vem de outros setores, nem de outras regiões do país, com exceção de uns poucos empresários mineiros que conseguiram furar um mercado extremamente fechado. Vem da própria operação do serviço e tem sua origem lá atrás, quando particulares começaram a prestar esse serviço, depois formaram suas pequenas empresas e cresceram. Em 1999, apenas 46 empresas operavam na capital e 51, na Região Metropolitana. Mas trata-se de empresas de grande porte, que detêm grandes fatias do mercado. Do total de viações, $40 \%$ possuem $64 \%$ da frota, cada qual com mais de 230 veículos, meia dúzia delas com quase 500 ônibus (Henry; Zioni, 1999:166-167).

A situação de São Paulo, que se poderia chamar de oligopolista, dá ao empresariado um enorme poder de negociação com os órgãos gestores, como se vê nos em- bates entre a prefeitura e o sindicato patronal. Sobretudo porque esse empresariado conseguiu cooptar o movimento sindical, convencendo-o que "o inimigo" é o poder público, uma vez que é ele quem projeta a rede de operações, definindo linhas, paradas, horários, frota e, principalmente, sistema de remuneração dos serviços.

O sistema de transporte coletivo de Belo Horizonte é bastante diferenciado. Em primeiro lugar, a operação do sistema sempre esteve em poder da iniciativa empresarial privada, responsabilizando-se o poder público apenas pelo planejamento e pela fiscalização. Além disso, Belo Horizonte manteve uma baixa concentração de capital e uma grande heterogeneidade de empresas de ônibus. Mesmo depois de sucessivos esforços de racionalização e modernização, por parte dos órgãos gestores, que resultaram em maior concentração nas outras capitais brasileiras, o município de Belo Horizonte apresentava o maior número de empresas, 54, maior mesmo que o Município de São Paulo, e uma frota média de 47,6 veículos por empresa, menor que nas outras capitais. Existe, pois, uma grande heterogeneidade entre empresas, que se expressa também no fato de algumas viações operarem uma só linha, outras, mais de 20 (Cançado et al., 1999). Isso não impede que tais empresas se aliem para fazer frente às exigências do poder público, devido à convergência de interesses entre grandes e pequenas.

Apesar de seu caráter essencial, os transportes coletivos estão em crise em todos os grandes centros urbanos do país. Isso se manifesta em altos níveis de congestionamento, poluição atmosférica, insegurança viária, longas esperas nas filas, viagens desconfortáveis. Além disso, com o aumento de carros particulares e de "peruas" em circulação, a deterioração das vias públicas e o crescimento do número de lombadas, registraram-se redução da velocidade média dos veículos de transporte coletivo, ${ }^{1}$ ampliação do tempo de percurso e aumento do desconforto imposto a usuários e motoristas.

As estatísticas também são reveladoras: se, no início dos anos 90, os ônibus municipais de São Paulo transportavam 150 milhões de passageiros ao mês, no final da década transportavam apenas 90 milhões. O transporte de passageiros por ônibus, que representava em $197744 \%$ de todos os deslocamentos, em 1997 caiu para 25,1\% desse total, perdendo para as viagens por motos, carros particulares, táxis e lotações, que representavam, na mesma data, $31,7 \%$ do total de deslocamentos. O mais impressionante é o percentual de deslocamentos que são feitos a pé 
$(34,4 \%)$, numa cidade das dimensões de São Paulo (Cançado et al., 1999:179). E, no dizer dos autores, esse dualismo entre mobilidade individual e coletiva mostra uma face perversa da cidade, em que a classe média se beneficia de ilhas de excelência de primeiro mundo, ao passo que as camadas populares são excluídas até mesmo do transporte coletivo.

A Região Metropolitana de Belo Horizonte contava, em janeiro de 2002, com uma frota bem menor que São Paulo (um total de 5 mil ônibus, aproximadamente). Naquela data, mês de férias, foram transportados 34,3 milhões de passageiros. Porém, diferentemente de São Paulo, o transporte alternativo não parece constituir grande problema, pois foi equacionado pela BHTrans, que licenciou um certo número de pequenas operadoras e exerce vigilância rigorosa nas ruas. O problema persiste em outros municípios da região, porém atenuado, pelo fato de os "perueiros" dos municípios vizinhos não poderem entrar em Belo Horizonte, o que coíbe um pouco sua atividade.

Cada viação organiza o trabalho de seus cobradores e motoristas, a fim de atender a especificações de linhas, itinerários, número de carros, horários, etc., feitas pelos órgãos gestores. O planejamento do serviço feito externamente à empresa facilita, de certo modo, o encaminhamento das insatisfações dos trabalhadores aos gestores externos, de tal modo que, em São Paulo, o empresariado e os trabalhadores se apresentam unidos em suas reivindicações. Isso parece ocorrer em menor medida em Belo Horizonte, onde o Sindicato dos Trabalhadores consegue manter clara a distinção entre patronato e poder público e vem atuando diligentemente em prol de conquistas para os trabalhadores. Por outro lado, a predominância de empresas pequenas e médias torna possível um relacionamento mais próximo entre patrões e empregados, mantendose práticas de gestão paternalista da mão-de-obra, concomitantemente com gestões mais profissionais, em outras companhias.

\section{CONDIÇÕES DE TRABALHO DOS MOTORISTAS}

Embora o contexto social e urbano do trabalho desses motoristas tenha diferenças entre as duas metrópoles, inclusive por causa do enorme diferencial de tamanho entre elas, foram tomadas precauções para permitir a comparabilidade dos resultados. Assim, apresentam-se a seguir alguns indicadores das condições de trabalho dos motoris- tas das Regiões Metropolitanas de Belo Horizonte e São Paulo, colocados lado a lado.

Existem muitas similaridades entre os motoristas de Belo Horizonte e os de São Paulo, tanto nas características pessoais como nos aspectos profissionais. Os profissionais de Belo Horizonte são, em média, um pouco mais novos que os paulistas (39,8 anos contra 42$)$, têm um ano a menos de profissão e cerca de um ano a menos na mesma empresa. O nível de instrução dos dois grupos é igualmente baixo: 36,3\% dos motoristas de Belo Horizonte e $37,4 \%$ dos paulistas cursaram no máximo até a 4a série do ensino fundamental. Nas duas regiões, o número de pessoas no domicílio é bastante próximo, e registrou-se um percentual semelhante de domicílios sustentados basicamente pelo rendimento do motorista $(60 \%$, em Belo Horizonte e 64\%, em São Paulo). Por outro lado, é mais freqüente as famílias belo-horizontinas contarem com menores de 16 anos $(82,6 \%)$ do que as paulistas $(73,3 \%)$ no orçamento familiar. Essas informações são apresentadas na Tabela 1.

Quanto às características da ocupação e da organização do trabalho, as vantagens são maiores ora para uma região, ora para outra, sendo difícil afirmar que a situação do motorista de Belo Horizonte seja melhor ou pior que a de São Paulo. Os profissionais de Belo Horizonte praticam jornadas mais curtas que os de São Paulo e percorrem trajetos menores; porém é menor a parcela dos que cumprem horário fixo e turno único $(57,9 \%$, em $\mathrm{BH}$, e $93,3 \%$, em SP) e significativamente mais elevada a proporção daqueles que fazem dois turnos de trabalho, a chamada "dupla pegada" (19,7\%), e horários irregulares

\section{TABELA 1}

Características Pessoais e Familiares dos Motoristas de Ônibus Regiões Metropolitanas de Belo Horizonte e São Paulo-Dez. 2000-Jan. 2002

\begin{tabular}{lrr}
\hline Características & $\begin{array}{r}\text { BeloHorizonte } \\
\text { (Jan. 2002) }\end{array}$ & $\begin{array}{r}\text { São Paulo } \\
\text { (Dez. 2000) }\end{array}$ \\
\hline Idade Média dos Motoristas (em anos) & 39,8 & 42 \\
Tempo de Profissão (em anos) & 10,9 & 11,9 \\
Tempo na Mesma Empresa (em anos) & 5,6 & 6,3 \\
Escolaridade Média & Fundamental & Fundamental \\
Incompleto & Incompleto \\
Né 1 a 4 Anos Cursados (em \%) & 36,3 & 37,4 \\
Domicílios com Menores de 16 Anos (em \%) & 4,1 & 4,2 \\
Só o Motorista Trabalha na Família (em \%) & 82,6 & 73,3 \\
Rendimento Familiar Médio (em reais) (1) & 60,0 & 64,0 \\
\hline
\end{tabular}

Fonte: Fundação Seade; Fundacentro. Pesquisa de Condições de Saúde e Segurança dos Motoristas.

(1) Valores correntes 
$(22,4 \%)$. Em São Paulo, esses dois percentuais ficam em torno de 3,0\%. Também é muito mais alto em Belo Horizonte o percentual de motoristas sem pausa para a refeição $(73,9 \%$, em BH, e 7,8\%, em SP). Esse diferencial não pode ser inteiramente explicado pela prática da "dupla pegada", que permitiria ao motorista almoçar em casa, uma vez que é muito maior a proporção de motoristas sem pausa $(73,9 \%)$ do que a daqueles que fazem dois turnos de trabalho (19,7\%) (Tabela 2).

Os ônibus dirigidos em Belo Horizonte parecem ter mais dispositivos que facilitam o trabalho do motorista do que os de São Paulo, notando-se especialmente a presença mais frequiente de direção ajustável, apoio anatômico para as costas, ajuste vertical do assento e cinto de segurança de três pontos. Quanto à posição do motor, que é fundamental para o conforto do motorista, em 77,3\% dos ônibus dirigidos em Belo Horizonte, ele localiza-se na parte central ou traseira do veículo. Esse aspecto não foi pesquisado em São Paulo, porque a maioria dos ônibus já não tem motor dianteiro. Uma situação, em que estão em vantagem os motoristas de São Paulo, refere-se à possibilidade de trabalharem sempre com o mesmo carro (Tabela 3).

Quanto às condições do ambiente interno do veículo, a situação parece melhor em Belo Horizonte, pois os ônibus de São Paulo apresentam com mais frequiência trepi-

\section{TABELA 2}

Características da Ocupação e da Organização do Trabalho dos Motoristas de Ônibus

Regiões Metropolitanas de Belo Horizonte e São Paulo-Dez. 2000-Jan. 2002

\begin{tabular}{lcr}
\hline $\begin{array}{l}\text { Características da Ocupaçãoe } \\
\text { Organização do Trabalho }\end{array}$ & $\begin{array}{c}\text { Belo Horizonte } \\
\text { (Jan. 2002) }\end{array}$ & $\begin{array}{r}\text { São Paulo } \\
\text { (Dez. 2000) }\end{array}$ \\
\hline Assalariado com Carteira de Trabalho & 100,0 & 95,1 \\
Assinada (em \%) & 689,00 & $1.036,00$ \\
Rendimento Médio (em reais) (1) & $7: 52$ & $10: 20$ \\
Jornada Média Diária (horas) & $1: 47$ & $2: 22$ \\
$\begin{array}{l}\text { Duração Média dos Percursos (horas) } \\
\text { Proporção dos que Trabalham com Horário Fixoe }\end{array}$ & 57,9 & 93,9 \\
Turno Unico (em \%) & 19,7 & 3,7 \\
$\begin{array}{l}\text { Proporção dos que Trabalham com Horário Fixoe } \\
\text { Turno Duplo (em \%) }\end{array}$ & 22,4 & 3,0 \\
Proporção dos que Trabalham em & 4,6 & 5,1 \\
Turnos Irregulares (em \%) & 3,0 & 2,9 \\
Motoristas sem Pausas de 5 Minutos ou Mais & & \\
Número Médio de Pausas de 5 Minutos ou Mais & 73,9 & 7,8 \\
$\begin{array}{l}\text { Proporção dos que Não Fazem Pausa para } \\
\text { Refeições (em\%) }\end{array}$ & & \\
\hline Fonte: Fundação Seade; Fundacentro. Pesquisa de Condições de Saúde e Segurança dos \\
Motoristas. \\
(1) Valores correntes.
\end{tabular}

dação, muito ruído, presença de gases tóxicos, ventilação inadequada (Tabela 3). Assim, pode-se dizer, de um modo geral, que o equipamento dos motoristas é melhor em Belo Horizonte do que em São Paulo.

As condições desfavoráveis de trabalho somam-se certos hábitos pessoais, que só fazem agravar as condições de saúde dos motoristas nas duas regiões (Tabela 4).

Na questão da saúde, os motoristas de Belo Horizonte apresentam menos queixas que os paulistanos. O dobro dos profissionais belo-horizontinos declarou-se livre de sintomas, em comparação com os paulistas (14,0\% e 7,2\%, respectivamente). Além disso, todos os sintomas pesquisados se revelaram mais freqüentes em São Paulo do que em Belo Horizonte. Não obstante, não pode ser menosprezada a presença em Belo Horizonte de percentuais expressivos de motoristas com problemas de obesidade, dores musculares, distúrbios gastrointestinais e vista irritada, além de outros problemas. Chama a atenção espe-

$$
\text { TABELA } 3
$$

Condições dos Veículos Dirigidos pelos Motoristas de Ônibus Regiões Metropolitanas de Belo Horizonte e São Paulo-Dez. 2000-Jan. 2002

\begin{tabular}{lcc} 
& \multicolumn{2}{c}{ Em porcentagem } \\
\hline Condição dos Ônibus & $\begin{array}{c}\text { Belo Horizonte } \\
\text { (Jan. 2002) }\end{array}$ & São Paulo \\
(Dez. 2000)
\end{tabular}

Motor Central ou Traseiro

DireçãoAjustável

\section{7,3}

\section{2,7}

DireçãoHidráulica

Cinto de Segurança com Três Pontos

$$
98,6
$$

50,8

Apoio Anatômiconas Costas

Ajuste Vertical do Assento

Ajuste para Alcance dos Pedais

Dirige Sempre o Mesmo Ônibus

Muita Trepidação

Muito Ruído

Emanaçãode Gases Tóxicos

Ventilação Inadequada

$$
82,7
$$

$$
91,4
$$

$$
98,2
$$$$
56,6
$$$$
25,5
$$$$
32,0
$$$$
5,6
$$$$
24,9
$$

Fonte: Fundação Seade; Fundacentro. Pesquisa de Condições de Saúde e Segurança dos Motoristas.

(1) Não foi pesquisado.

TABELA 4

Hábitos Pessoais dos Motoristas

Regiões Metropolitanas de Belo Horizonte e São Paulo-Dez. 2000-Jan. 2002

\begin{tabular}{lcc}
\hline Hábitos Pessoais & $\begin{array}{c}\text { Em porcentagem } \\
\text { Belo Horizonte } \\
\text { (Jan. 2002) }\end{array}$ & $\begin{array}{c}\text { São Paulo } \\
\text { (Dez. 2000) }\end{array}$ \\
\hline Fuma & 23,5 & 31,4 \\
Ingere Bebida Alcoólica & 38,4 & 39,1 \\
Não Pratica Esporte & 57,0 & 71,9 \\
\hline
\end{tabular}

Fonte: Fundação Seade; Fundacentro. Pesquisa de Condições de Saúde e Segurança dos Motoristas. 
cialmente a questão da obesidade, que aflige metade dos motoristas belo-horizontinos e $61,2 \%$ dos paulistas. A tensão e o estresse, sintoma que não foi pesquisado em São Paulo, atinge 38,5\% dos motoristas de Belo Horizonte (Tabela 5).

Verificou-se, nas respectivas pesquisas de campo, uma alta incidência de violência dentro dos ônibus, maior em Belo Horizonte do que em São Paulo, especialmente assaltos à mão armada e agressões verbais. Em 2000 e 2002, respectivamente, $38,5 \%$ dos profissionais paulistas e $43,4 \%$ dos belo-horizontinos indicaram a ocorrência de um assalto à mão armada no ônibus em que trabalharam nos 12 meses anteriores (Tabela 6).

Toda essa violência urbana tem várias implicações. Sua consequiência direta reside no fato de $81,8 \%$ dos motoristas de Belo Horizonte e 78,0\% dos paulistas trabalharem com medo de serem assaltados. Também são indicados pelos profissionais de Belo Horizonte outros medos declarados pelos paulistas, embora com freqüência menor, ainda que em patamares elevados, pois $51,5 \%$ declarou ter medo de ser demitido e 58,9\%, de ficar doente (Tabe1a 7). Tanto em uma como em outra região, a freqüência dos diversos medos com que convivem esses profissionais só pode ter consequiências nefastas sobre sua saúde, como se verá a seguir.

\section{COMO AS CONDIÇÕES DE TRABALHO AFETAM A SAÚDE DOS MOTORISTAS}

Para testar a relação de sintomas de saúde com as condições de trabalho e hábitos de vida dos motoristas, afastando assim a hipótese de que esta relação seja aleatória, podendo acometer qualquer indivíduo da população, os resultados foram submetidos a análise estatística. A técnica escolhida foi a regressão logística, aconselhável quando a variável a ser analisada (variável dependente) tem natureza dicotômica. Essa técnica permite quantificar o grau de associação entre cada variável dependente, no caso os diversos sintomas de morbidade, com a presença ou ausência de certas condições de trabalho e hábitos de vida. A medida de associação resultante chama-se odds ratio, que vem a ser a chance de ocorrência de um sintoma em função de uma dada variável explicativa, em presença das outras variáveis introduzidas no modelo (Ferreira; Watanabe, 1996).

O conceito de chance - termo técnico em estatística pode ser entendido como a razão entre a proporção de motoristas com um dado sintoma e a proporção dos que

\section{TABELA 5}

Motoristas de Ônibus, segundo Sintomas Relativos à Saúde Regiões Metropolitanas de Belo Horizonte e São Paulo-Dez. 2000-Jan. 2002

\begin{tabular}{lcc} 
& & Em porcentagem \\
\hline Sintomas Relativos à Saúde & $\begin{array}{c}\text { Belo Horizonte } \\
\text { (Jan. 2002) }\end{array}$ & $\begin{array}{c}\text { São Paulo } \\
\text { (Dez. 2000) }\end{array}$ \\
\hline Obesidade ePré-Obesidade(1) & 50,1 & 61,2 \\
Dores nos Ombros, Braços, Pernas & 33,0 & 54,3 \\
Problemas de Coluna & 29,4 & 41,2 \\
Varizes & 10,8 & 17,7 \\
Vista Irritada & 33,1 & 54,7 \\
Problemas Gastrointestinais & 23,8 & 29,4 \\
Problemas Auditivos & 12,9 & 18,8 \\
Problemas do Sono & 13,2 & 17,9 \\
Problemas Respiratórios & 11,7 & 15,7 \\
Estresse & 38,5 & $(2)$ \\
Hipertensão Arterial & 8,2 & 15,9 \\
\hline
\end{tabular}

Fonte: Fundação Seade; Fundacentro. Pesquisa de Condições de Saúde e Segurança dos Motoristas.

(1) São consideradas obesas e pré-obesas as pessoas com IMC maior ou igual a 25. O IMCIndice de Massa Corporal é obtido dividindo-se o peso pelo quadrado da altura do indivíduo.

(2) Não foi pesquisado.

\section{TABELA 6}

Motoristas de Ônibus que Sofreram Ocorrência de Violência dentro do Ônibus, segundo Tipo de Ocorrência

Regiões Metropolitanas de Belo Horizonte e São Paulo-Dez. 2000-Jan. 2002

\begin{tabular}{lcc} 
& \multicolumn{2}{c}{ Em porcentagem } \\
\hline Tipo de Ocorrência & $\begin{array}{c}\text { Belo Horizonte } \\
\text { (Jan. 2002) }\end{array}$ & $\begin{array}{r}\text { São Paulo } \\
\text { (Dez. 2000) }\end{array}$ \\
\hline Assalto à Mão Armada & 43,4 & 38,5 \\
Assalto sem Arma & 7,4 & 13,8 \\
Agressão Física & 6,8 & 6,9 \\
Agressão Verbal & 40,1 & 26,6 \\
\hline
\end{tabular}

Fonte: Fundação Seade; Fundacentro. Pesquisa de Condições de Saúde e Segurança dos Motoristas.

\section{TABELA 7}

Motoristas de Ônibus, segundo Medos Declarados

Regiões Metropolitanas de Belo Horizonte e São Paulo-Dez. 2000-Jan. 2002

\begin{tabular}{lcc}
\hline Medos Declarados & $\begin{array}{c}\text { Em porcentagem } \\
\text { Belo Horizonte } \\
\text { (Jan. 2002) }\end{array}$ & $\begin{array}{c}\text { SãoPaulo } \\
\text { (Dez. 2000) }\end{array}$ \\
\hline Ser Assaltado & 81,8 & 78,0 \\
Sofrer Acidente & 69,9 & 70,9 \\
Morrer & 59,5 & 67,6 \\
Ficar Doente & 58,9 & 63,2 \\
Ser Demitido & 51,5 & 56,8 \\
\hline
\end{tabular}

Fonte: Fundação Seade; Fundacentro. Pesquisa de Condições de Saúde e Segurança dos Motoristas.

não referiram esse sintoma. A razão de chances representa a mudança na chance de o motorista apresentar um determinado sintoma, quando passa de uma categoria de 
condição de trabalho para outra, mantendo inalteradas as demais condições. Desse modo, uma razão de chance igual a 1 indica que a mudança de categoria não afeta o aparecimento do sintoma.

Os sintomas de morbidade submetidos a análise foram obesidade, dores osteomusculares, problemas gastrointestinais, vista irritada, problemas respiratórios, problemas auditivos, problemas do sono e estresse. A cada um desses sintomas foram relacionadas as condições de trabalho e os hábitos pessoais considerados pertinentes, segundo o saber da medicina ocupacional. A idade foi levada em consideração em todas as análises de associação dos sintomas com as condições de trabalho. Para obtenção dos modelos finais, foi adotado um nível de significância de $10 \%$ na maioria dos casos.

As variáveis explicativas aparecem, em diferentes combinações, nos vários modelos. Para não citar repetidamente qual é o grupo de referência em cada um deles, apresentase a seguir uma listagem dos grupos de referência de todas as variáveis:

- sobre as características pessoais e hábitos, foram tomados como base de comparação os motoristas com idade de 22 anos, pressão arterial normal, que não bebem, que praticam esporte e não fumam;

- com relação à organização do trabalho, motoristas que exercem suas atividades em turno fixo, com jornada de até 8:39 e nenhuma pausa de 5 minutos ou mais (grupo de referência para duas variáveis: tem pausa e número de pausas);

- quanto às características dos veículos, motoristas que dirigem ônibus com direção ajustável, apoio para as costas, ajuste vertical do banco, sem trepidação, sem ruído, sem emanação de gases tóxicos e com ventilação adequada;

- finalmente, quanto aos medos, os motoristas sem medo de assalto, de acidente e de demissão.

A seguir, são apresentados e discutidos os resultados das regressões logísticas referentes a cada um dos sintomas acima relacionados. Essa análise estatística faz sentido dentro do que ficou exposto, isto é, que uma sintomatologia referida pelas próprias pessoas representa razoavelmente bem seu estado de saúde.

\section{Obesidade}

A obesidade e a pré-obesidade, medidas pelo Índice de Massa Corporal, ${ }^{2}$ constituem um grave problema de saúde dos motoristas, tanto em Belo Horizonte como em
São Paulo. Esse problema foi examinado em função da idade, extensão da jornada, existência e duração das pausas de descanso, número de pausas de descanso, existência ou não de pausa para refeição, prática de esporte e hipertensão arterial.

Nos modelos ajustados, a idade apresentou a maior importância para explicar a chance de um indivíduo ser obeso ou pré-obeso. Essa chance aumenta geometricamente à razão de 1,04 a cada ano adicional de idade em São Paulo e 1,03\% em Belo Horizonte. Aos 40 anos, é $89 \%$ maior na primeira região e $60,4 \%$ maior na segunda, com relação à idade de referência.

A extensão da jornada também se revelou importante. Em São Paulo, a chance de motoristas que trabalham 8:40 horas ou mais serem obesos ou pré-obesos é 31,5\% maior do que a de motoristas com jornadas menos extensas; o fazer ou não esporte não mostrou significância estatística. Por outro lado, em Belo Horizonte, a ausência de esportes aumenta em $27,6 \%$ esse risco para todos os motoristas, independentemente da jornada.

O número de pausas para descanso durante o trabalho mostrou-se importante em Belo Horizonte, porém não obteve significância estatística em São Paulo. Na primeira metrópole, a introdução de uma pausa na jornada reduz em $8,7 \%$ a chance de o motorista se tornar obeso; com três pausas haveria redução de $23,8 \%$.

A hipertensão arterial pode desenvolver-se devido a vários fatores de risco, agindo conjuntamente (Cordeiro et al., 1993). Entre eles, fatores genéticos e ocupacionais, como o estresse, associados a obesidade, sedentarismo, ingestão de álcool, hábito de fumar. Por esse motivo foi introduzida nos modelos de obesidade como variável de controle.

\section{Dores Osteomusculares}

As variáveis dores nos ombros, braços, pernas e problemas de coluna, e também varizes, ${ }^{3}$ foram pesquisadas conjuntamente, num único sintoma denominado dores osteomusculares. Buscou-se verificar a associação desse sintoma com certas condições dos ônibus (apoio para as costas, banco com ajuste vertical, direção ajustável, trepidação, muito ruído), da organização do trabalho (extensão da jornada, presença ou não de pausas de descanso, número dessas pausas) ou de hábitos pessoais do motorista (prática de esporte). Essas dores constituem o maior problema de saúde dos motoristas, depois da obesidade, como pode ser conferido na Tabela 5 . 
Em São Paulo, quase todas as variáveis consideradas apresentaram significância estatística, dentro do modelo ajustado. Assim, a chance de o motorista sofrer dores, quando dirige ônibus com trepidação, é 2,5 vezes maior do que quando não há trepidação; quando o banco não tem ajuste vertical, a chance é $1,5 \mathrm{vez}$ maior ou, mais precisamente, 53\% maior; quando não existe apoio anatômico para as costas, a chance é $38 \%$ maior; quando o motorista não pratica esporte, ele tem $28 \%$ a mais de chance de apresentar dores; e quando tem pelo menos uma pausa de 5 minutos ou mais para descanso em sua jornada de trabalho, a chance diminui cerca de 5\%; com quatro pausas, a redução é de $17 \%$. A idade, introduzida no modelo para controle, apresentou em São Paulo certa importância explicativa: a chance de o motorista apresentar dores cresce geometricamente a uma razão de 1,01 a cada ano adicional de idade, de tal maneira que, aos 40 anos, é $30 \%$ maior que aos 22 anos, idade de referência.

O papel da idade, que assume importância neste e em outros sintomas, está completamente em desacordo com o que seria de se esperar, dada a relativa juventude dos motoristas, todos em plena idade ativa. Sabe-se que o envelhecimento funcional precoce não está necessariamente associado à idade cronológica. Estudos conduzidos na Europa e também no Brasil (Ilmarinen, 1999; Bellusci; Fischer, 1999; Fischer, 2002) indicam que boas condições de trabalho e estilo de vida saudável permitem a manutenção da saúde e da capacidade de trabalho até idades avançadas.

Em Belo Horizonte, um menor número de variáveis está associado ao aparecimento de dores osteomusculares. A existência de trepidação dentro do ônibus foi a variável decisiva, pois ela aumenta 2,1 vezes a chance de desenvolver dores, com relação aos que não estão sujeitos a ela, com alta significância estatística. A extensão da jornada mostrou-se importante no modelo ajustado para Belo Horizonte: os motoristas que trabalham 8:40 horas ou mais têm chance $41 \%$ maior de apresentar dores do que os que trabalham até 8:39 horas diárias.

Assim, a trepidação dentro do ônibus é de longe a condição de trabalho que mais sofrimento causa aos motoristas das duas metrópoles. Provavelmente ela tem a ver com o modelo de ônibus usado e seu estado de conservação e também com a qualidade das vias públicas. A eliminação da trepidação deveria ser objeto de políticas voltadas tanto para a melhoria das vias públicas, como da garantia de um equipamento mais adequado para o trabalho dos motoristas.

\section{Problemas Gastrointestinais}

Foram consideradas, na análise deste sintoma, a extensão da jornada, a existência ou não de pausas de descanso e seu número, se o motorista tem ou não pausa para refeição, o medo de assalto, medo de demissão, e consumo de bebida alcoólica.

Em Belo Horizonte, o medo de assalto dentro do ônibus é a variável mais importante para explicar o comportamento dos distúrbios gastrointestinais, aumentando em 72,6\% a chance de seu aparecimento, com relação aos motoristas que não expressaram essa preocupação. Também o consumo de bebida alcoólica aumenta essa chance em $43,4 \%$. A associação dos problemas gastrointestinais com a variável Tempausa de 5 minutos ou mais, que se apresentou positiva, merece mais investigação, pois pode haver outras variáveis que estejam interferindo no resultado. Por outro lado, o número de pausas durante o trabalho atua no sentido inverso: a chance de distúrbios gastrointestinais diminui $9,4 \%$ a cada nova pausa acrescentada à jornada do motorista. Assim, com três pausas, tal chance sofreria uma redução de $25,7 \%$. Em São Paulo, apenas o medo de assalto mostrou-se importante, aumentando em $43,8 \%$ a chance desses problemas.

É interessante notar que a associação entre o medo de assalto e a chance de problemas gástricos é maior em Belo Horizonte do que em São Paulo, correspondendo a uma incidência maior de violência dentro dos veículos na primeira região (Tabela 6). Mas esse medo afeta a saúde dos motoristas das duas metrópoles de modo alarmante, o que constitui uma razão a mais para que sejam implementadas políticas públicas de redução da violência.

\section{Vista Irritada}

Quanto a este problema, foram considerados a emanação de gases tóxicos dentro do ônibus, a existência ou não de ventilação adequada e o hábito de fumar. Em São Paulo, as condições de trabalho mais importantes para explicar o comportamento da chance de vista irritada, depois de controlada a idade, são a emanação de gases tóxicos, que dobra essa chance, e a ventilação inadequada, que a aumenta em $67 \%$.

Em Belo Horizonte, mostraram-se importantes a ventilação inadequada e a emanação de gases tóxicos, que incrementam, respectivamente, em $87 \%$ e $69 \%$ a chance do aparecimento desse problema.

A idade, variável de controle, também tem um papel a desempenhar nas duas regiões. Em São Paulo, a chance desse problema aumenta a uma razão geométrica de 1,02 a cada 
ano adicional de idade, o que resulta em um aumento de $47 \%$ aos 40 anos de idade. Em Belo Horizonte, a taxa de aumento é $1,03 \%$ ao ano, de tal maneira que, aos 40 anos, essa chance assume um valor $84 \%$ vezes maior.

\section{Problemas Respiratórios}

Para este sintoma, foram consideradas as mesmas variáveis que no caso da vista irritada. Em São Paulo, o modelo acusou associações significativas entre esses problemas e emanação de gases tóxicos e ventilação: a emanação de gases tóxicose a ventilação inadequada aumentam em $75 \%$ e $48 \%$, respectivamente, a chance de o motorista desenvolver problemas respiratórios. Já em Belo
Horizonte, não foi possível ajustar um modelo ao nível de $10 \%$ para esse sintoma.

\section{Problemas Auditivos}

Surgiram entre os motoristas das duas metrópoles queixas de perda de audição. Analisou-se, portanto, se haveria associação entre essa perda e a presença de muito ruído dentro dos veículos. Nas duas metrópoles essa relação mostrou-se altamente significante e de magnitude considerável, mesmo depois de controlada a variável idade. Tanto em São Paulo como em Belo Horizonte, a chance do surgimento de problemas de audição em motoristas de ônibus com muito ruído é mais que duas vezes maior, em

TABELA 8

Modelo Logístico Ajustado para Sintomas de Morbidade dos Motoristas de Ônibus Região Metropolitana de São Paulo - Dez. 2000

\begin{tabular}{|c|c|c|c|c|c|c|c|}
\hline \multirow{2}{*}{ Sintomas } & \multirow{2}{*}{ Variável } & \multirow{2}{*}{ Coeficiente } & \multirow{2}{*}{ Erro-Padrão } & \multirow{2}{*}{$\begin{array}{l}\text { Signifi- } \\
\text { cância }\end{array}$} & \multirow{2}{*}{$\begin{array}{l}\text { Razão de } \\
\text { Chances }\end{array}$} & \multicolumn{2}{|c|}{ Intervalo de Confiança (95\%) } \\
\hline & & & & & & Limite Inferior & Limite Superior \\
\hline \multirow[t]{4}{*}{ Obesidade } & Idade & 0,0353 & 0,0062 & $<0,0001$ & 1,0359 & 1,0234 & 1,0486 \\
\hline & Hipertensão Arterial & 0,4627 & 0,1541 & 0,0027 & 1,5884 & 1,1743 & 2,1485 \\
\hline & Extensão de $8: 40$ ou Mais & 0,2737 & 0,1122 & 0,0147 & 1,3148 & 1,0553 & 1,6381 \\
\hline & Constante & $-0,4396$ & 0,1528 & 0,0040 & & & \\
\hline \multirow[t]{7}{*}{ Dores Osteomusculares } & Trepidação & 0,9035 & 0,1123 & $<0,0001$ & 2,4681 & 1,9804 & 3,0759 \\
\hline & Número de Pausas & $-0,0475$ & 0,0177 & 0,0075 & 0,9536 & 0,9210 & 0,9874 \\
\hline & Sem Apoio para Costas & 0,3211 & 0,1250 & 0,0102 & 1,3787 & 1,0792 & 1,7613 \\
\hline & Idade & 0,0147 & 0,0060 & 0,0152 & 1,0148 & 1,0028 & 1,0269 \\
\hline & Banco sem Ajuste Vertical & 0,4268 & 0,1890 & 0,0240 & 1,5324 & 1,0579 & 2,2197 \\
\hline & Não Pratica Esportes & 0,2465 & 0,1155 & 0,0329 & 1,2796 & 1,0203 & 1,6047 \\
\hline & Constante & $-0,4575$ & 0,2165 & 0,0346 & & & \\
\hline \multirow[t]{5}{*}{ Vista Irritada } & Gases Tóxicos & 0,6741 & 0,1485 & $<0,0001$ & 1,9623 & 1,4667 & 2,6255 \\
\hline & Ventilação Inadequada & 0,5114 & 0,1028 & $<0,0001$ & 1,6676 & 1,3634 & 2,0398 \\
\hline & Idade & 0,0214 & 0,0056 & 0,0001 & 1,0216 & 1,0105 & 1,0328 \\
\hline & Fumante & 0,2018 & 0,1052 & 0,0551 & 1,2236 & 0,9956 & 1,5038 \\
\hline & Constante & $-0,6665$ & 0,1289 & $<0,0001$ & & & \\
\hline Problemas & Medo de Assalto & 0,3633 & 0,1374 & 0,0082 & 1,4381 & 1,0986 & 1,8824 \\
\hline Gastrointestinais & Constante & $-1,2075$ & 0,1244 & $<0,0001$ & & & \\
\hline \multirow[t]{3}{*}{ Problemas Auditivos } & Ruído & 0,7959 & 0,1408 & $<0,0001$ & 2,2165 & 1,6820 & 2,9209 \\
\hline & Idade & 0,0228 & 0,0072 & 0,0014 & 1,0231 & 1,0088 & 1,0375 \\
\hline & Constante & $-2,5276$ & 0,1856 & $<0,0001$ & & & \\
\hline \multirow[t]{3}{*}{ Problemas do Sono } & Medo de Acidente & 0,3794 & 0,1526 & 0,0129 & 1,4614 & 1,0837 & 1,9708 \\
\hline & Extensão de 8:40 ou Mais & 0,1125 & 0,1441 & 0,4350 & 1,1191 & 0,8437 & 1,4843 \\
\hline & Constante & $-1,9589$ & 0,1679 & $<0,0001$ & & & \\
\hline \multirow[t]{3}{*}{ Problemas Respiratórios } & Gases Tóxicos & 0,5624 & 0,1693 & 0,0009 & 1,7549 & 1,2595 & 2,4452 \\
\hline & Ventilação Inadequada & 0,3931 & 0,1361 & 0,0039 & 1,4815 & 1,1346 & 1,9346 \\
\hline & Constante & $-1,9560$ & 0,0920 & $<0,0001$ & & & \\
\hline
\end{tabular}

Fonte: Fundação Seade; Fundacentro. Pesquisa de Condições de Saúde e Segurança dos Motoristas. 
comparação com a dos motoristas que não registraram a existência de ruído dentro do ônibus.

Por outro lado, a idade acrescenta perda auditiva (presbiacusia). No modelo ajustado para São Paulo, a chance desse problema aumenta geometricamente 1,02 a cada ano adicional de idade, o que resulta em uma chance $51 \%$ maior aos 40 anos de idade. Para Belo Horizonte, o incremento anual é 1,04, levando, aos 40 anos, a uma perda cerca de $100 \%$ maior, com relação à idade de referência.

\section{Problemas do Sono}

Foram considerados, com relação ao sono, a extensão da jornada, a "dupla pegada" em Belo Horizonte, o horário alternante ou irregular, a prática do turno noturno, os medos de acidente, assalto e demissão e a ingestão de bebida alcoólica. Em São Paulo, a única variável que se revelou significante foi o medo de acidente, que aumenta em $46 \%$ a chance de os motoristas terem problemas de

TABELA 9

Modelo Logístico Ajustado para Sintomas de Morbidade dos Motoristas de Ônibus Região Metropolitana de Belo Horizonte - Jan. 2002

\begin{tabular}{|c|c|c|c|c|c|c|c|}
\hline \multirow{2}{*}{ Sintomas } & \multirow{2}{*}{ Variável } & \multirow{2}{*}{ Coeficiente } & \multirow{2}{*}{ Erro-Padrão } & \multirow{2}{*}{$\begin{array}{l}\text { Signifi- } \\
\text { cância }\end{array}$} & \multirow{2}{*}{$\begin{array}{l}\text { Razão de } \\
\text { Chances }\end{array}$} & \multicolumn{2}{|c|}{ Intervalo de Confiança (95\%) } \\
\hline & & & & & & Limite Inferior & Limite Superior \\
\hline \multirow[t]{8}{*}{ Obesidade } & Idade & 0,0262 & 0,0081 & 0,0013 & 1,0266 & 1,0103 & 1,0431 \\
\hline & Extensão de 8:40 ou Mais e & & & & & & \\
\hline & Não Pratica Esportes (Interação) & $-0,8204$ & 0,3601 & 0,0227 & 0,4403 & 0,2174 & 0,8917 \\
\hline & Número de Pausas & $-0,0908$ & 0,0424 & 0,0320 & 0,9132 & 0,8404 & 0,9922 \\
\hline & Hipertensão Arterial & 0,4626 & 0,2562 & 0,0709 & 1,5883 & 0,9613 & 2,6241 \\
\hline & Não Pratica Esporte & 0,2437 & 0,1466 & 0,0965 & 1,2760 & 0,9573 & 1,7007 \\
\hline & Extensão de $8: 40$ ou Mais & 0,3337 & 0,2812 & 0,2354 & 1,3961 & 0,8045 & 2,4227 \\
\hline & Constante & $-0,9490$ & 0,3526 & 0,0071 & & & \\
\hline \multirow[t]{5}{*}{ Dores Osteomusculares } & Trepidação & 0,7325 & 0,1523 & $<0,0001$ & 2,0803 & 1,5433 & 2,8041 \\
\hline & Extensão de 8:40 ou mais & 0,3436 & 0,1754 & 0,0501 & 1,4100 & 0,9998 & 1,9883 \\
\hline & Direção Ajustável & 0,2466 & 0,1366 & 0,0709 & 0,7814 & 0,5979 & 1,0213 \\
\hline & Idade & 0,0121 & 0,0078 & 0,1192 & 1,0122 & 0,9969 & 1,0278 \\
\hline & Constante & $-0,4051$ & 0,1800 & 0,0244 & & & \\
\hline \multirow[t]{4}{*}{ Vista Irritada } & Ventilação Inadequada & 0,6278 & 0,1544 & $<0,0001$ & 1,8734 & 1,3842 & 2,5355 \\
\hline & Idade & 0,0338 & 0,0082 & $<0,0001$ & 1,0344 & 1,0179 & 1,0512 \\
\hline & Gases Tóxicos & 0,5236 & 0,2863 & 0,0675 & 1,6881 & 0,9631 & 2,9589 \\
\hline & Constante & $-1,5243$ & 0,1751 & $<0,0001$ & & & \\
\hline Problemas & Medo de Assalto & 0,5456 & 0,2204 & 0,0133 & 1,7256 & 1,1203 & 2,6578 \\
\hline \multirow[t]{4}{*}{ Gastrointestinais } & Bebida & 0,3606 & 0,1539 & 0,0192 & 1,4342 & 1,0606 & 1,9392 \\
\hline & Tem Pausa de 5 Minutos ou Mais & 0,8319 & 0,4494 & 0,0642 & 2,2977 & 0,9523 & 5,5441 \\
\hline & Número de Pausas & $-0,0988$ & 0,0552 & 0,0733 & 0,9059 & 0,813 & 1,0094 \\
\hline & Constante & $-2,2972$ & 0,4577 & $<0,0001$ & & & \\
\hline \multirow[t]{3}{*}{ Problemas Auditivos } & Ruído & 0,8396 & 0,1944 & $<0,0001$ & 2,3155 & 1,5819 & 3,3892 \\
\hline & Idade & 0,0410 & 0,0114 & 0,0003 & 1,0419 & 1,0189 & 1,0654 \\
\hline & Constante & $-3,0093$ & 0,2655 & $<0,0001$ & & & \\
\hline \multirow[t]{3}{*}{ Problemas do Sono } & Medo de Acidente & 0,5979 & 0,229 & 0,0090 & 1,8182 & 1,1607 & 2,8481 \\
\hline & Extensão de 8:40 ou Mais & 0,4671 & 0,2297 & 0,0420 & 1,5954 & 1,0170 & 2,5026 \\
\hline & Constante & $-2,4063$ & 0,2082 & $<0,0001$ & & & \\
\hline \multirow[t]{5}{*}{ Estresse } & Medo de Acidente & 0,5382 & 0,1545 & 0,0005 & 1,7129 & 1,2653 & 2,3189 \\
\hline & Turno Alternante ou Irregular & $-0,4593$ & 0,1587 & 0,0038 & 0,6317 & 0,4629 & 0,8621 \\
\hline & Medo de Assalto & 0,4979 & 0,1907 & 0,0090 & 1,6453 & 1,1321 & 2,3911 \\
\hline & Extensão de 8:40 ou Mais & 0,4302 & 0,1767 & 0,0149 & 1,5376 & 1,0876 & 2,1738 \\
\hline & Constante & $-0,9756$ & 0,2245 & 0,0000 & & & \\
\hline
\end{tabular}

Fonte: Fundação Seade; Fundacentro. Pesquisa de Condições de Saúde e Segurança dos Motoristas. 
sono, com relação aos que não têm esse medo. A extensão da jornada, mesmo que não significante, foi mantida no modelo como variável de controle, com a finalidade de tornar mais clara a associação entre as outras variáveis e o sintoma.

Também em Belo Horizonte, a variável mais importante para explicar o comportamento da chance de o motorista ter problemas do sono foi o medo de acidente. De fato, os motoristas que apontaram esse medo têm uma chance $82 \%$ maior do que os que não o declararam. Além disso, o efeito da extensão da jornada também é considerável, pois aumenta em 59,5\% a chance do problema, com relação a motoristas com jornadas mais curtas.

A presença do estresse foi investigada em Belo Horizonte, porém não em São Paulo. As variáveis consideradas foram: medo de acidente, medo de assalto, medo de ser demitido, extensão da jornada, turno alternante ou irregular, turno noturno e "dupla pegada". Mostraram-se significantes o medo de acidente, o medo de assalto, a extensão da jornada e o horário alternante ou irregular, todos com alto poder explicativo. Porém a variável mais importante foi o medo de acidente, que aumenta em $71 \%$ a chance de estresse, com relação aos motoristas que não têm essa preocupação. O medo de assalto e a extensão da jornada aumentam a chance de estresse, respectivamente, em $65 \%$ e $54 \%$. O horário alternante ou irregular mostrou um efeito curioso: a hipótese era de que ele aumentaria a chance de estresse; porém, no modelo ajustado, ele a reduz em $37 \%$. É possível que as mudanças de horário de trabalho tenham um efeito protetor, por alternarem horários desfavoráveis, com entrada muito cedo ou saída muito tarde da noite, quando é maior a possibilidade de assaltos.

Os modelos ajustados finais, com especificação de algumas estatísticas que podem interessar aos leitores, são apresentados nas Tabelas 8 e 9 .

\section{CONSIDERAÇÕES FINAIS}

Verificou-se a existência de muitas similaridades entre os motoristas de ônibus de Belo Horizonte e os de São Paulo, tanto nas características pessoais como nos aspectos referentes à ocupação.

Quanto às características da ocupação e da organização do trabalho, verificaram-se vantagens ora para uma região, ora para outra, sendo difícil afirmar em que local a situação está melhor. Os motoristas de Belo Horizonte praticam jornadas mais curtas que os de São Paulo e têm trajetos menores a percorrer. Entretanto, são mais baixos os percentuais dos que cumprem horário fixo e turno único e significativamente mais elevadas as proporções daqueles que fazem dois turnos de trabalho, a chamada "dupla pegada", e dos que cumprem horários irregulares. Além disso, é muito mais alto em Belo Horizonte o percentual de motoristas sem pausa para a refeição.

Por outro lado, o equipamento usado em Belo Horizonte parece ser de melhor qualidade que o de São Paulo. É mais freqüente em Belo Horizonte a presença de dispositivos que oferecem mais conforto ao motorista (direção ajustável, direção hidráulica, cinto de segurança de três pontos, apoio anatômico para as costas, ajuste vertical do assento, ajuste para alcance dos pedais), e menos comuns as queixas de trepidação, ruído e gases dentro dos ônibus.

Mesmo assim, os dois grupos de profissionais enfrentam condições de trabalho muito duras e apresentam sérios problemas de saúde. Dentro do conceito, hoje consensual na literatura especializada, da validade de sintomas referidos para diagnosticar condições de morbidade, é perfeitamente cabível proceder-se à busca de explicações para os problemas de saúde dos motoristas nas condições em que vivem e trabalham. De fato, a análise estatística efetivada revelou a existência de relações muito importantes entre algumas das condições de trabalho e a sintomatologia de morbidade declarada pelos motoristas, nas duas regiões.

Essa análise foi realizada, de um lado, da ótica do instrumento de trabalho do motorista - o ônibus. Verificouse que várias características dos ônibus - a trepidação, o ajuste vertical do banco, apoio anatômico para as costas, a emanação de gases tóxicos, ventilação inadequada e muito ruído - estão associados a diversos problemas de saúde, como dores osteomusculares, vista irritada, problemas respiratórios e auditivos.

A trepidação, causada não só pelas condições dos ônibus mas também pela qualidade das vias públicas, mais do que dobra a chance de dores osteomusculares, acrescentando um sofrimento inútil aos motoristas das duas regiões. Uma política pública que realmente valorize o transporte coletivo há que enfrentar não só o tipo de ônibus e sua conservação, como também o estado das vias públicas.

Outros aspectos analisados dizem respeito à organização do trabalho dos motoristas, como a extensão da jornada e a existência e freqüência de pausas para descanso durante a jornada. A extensão da jornada mostrou-se associada, nos modelos ajustados, à obesidade, ao aparecimento de dores osteomusculares, problemas do sono e 
estresse. Ora, existem estudos que mostram que uma pessoa muito cansada e sonolenta oferece o mesmo risco, ao volante, que uma pessoa alcoolizada (Rajaratnam; Arendt, 2001). Não é à toa que um dos grandes medos dos motoristas é serem envolvidos em acidentes.

Ao lado da redução da jornada diária, principalmente em São Paulo, onde se praticam jornadas extremamente longas (10 horas e 20 minutos, em média), essa situação poderia ser amenizada pela introdução de mais pausas de descanso. Por exemplo, com um melhor planejamento do trabalho, os longos percursos poderiam ser quebrados por pausas mais freqüentes, que permitiriam ao motorista movimentar-se e fazer alguns exercícios bem orientados para braços e pernas, além de relaxar a atenção continuada que o trânsito exige dele ao volante, reduzindo o cansaço e o estresse. Em alguns dos modelos ajustados, um número maior de pausas, controladas as outras variáveis, mostrou-se associado a menor incidência de obesidade, dores musculares e problemas gastrointestinais.

Há problemas de âmbito mais geral, que incidem em toda a sociedade e cuja solução requer medidas sociais e políticas mais amplas. Deles resulta que cada motorista é acompanhado, na sua labuta diária, por uma coleção de medos (ser assaltado, sofrer acidente, morrer, ficar doente, ser demitido) que repercutem sobre sua saúde, gerando estresse, problemas do sono e outros sintomas. Nos modelos ajustados no presente estudo, ficou constatada a associação entre o medo de assalto e problemas gastrointestinais, e o medo de acidente e problemas do sono e estresse.

A incidência de episódios de violência dentro dos ônibus é tão alta, que se tornou corriqueira, quando deveria mobilizar a sociedade e os poderes públicos a tomarem providências enérgicas, pois coloca em risco não só a saúde do motorista, como também sua vida e a dos passageiros. Uma iniciativa nesse sentido é a experiência, em curso em Belo Horizonte, de instalação de câmeras de TV nos ônibus. Em princípio, a possibilidade de identificação de agressores tenderia a dissuadir a prática da violência dentro dos veículos.

As associações observadas entre idade e vários dos sintomas de morbidade não podem ser atribuídas simplesmente à idade cronológica, pois sabe-se que os motoristas sofrem um desgaste incompatível com sua idade cronológica, devido às más condições de trabalho. Medidas que venham a amenizar essas condições também enfraquecerão os efeitos da idade sobre a saúde dos motoristas.
Pelo que foi visto, pode-se concluir que, nas duas metrópoles, os motoristas do transporte de passageiros estão sendo submetidos a condições de trabalho muito penosas, que afetam sua saúde e segurança, como também a segurança dos passageiros. Isso indica a necessidade de implementação de medidas preventivas de múltiplo alcance, que busquem, simultaneamente, melhorar a qualidade dos veículos em circulação, fiscalizar de forma mais eficiente o cumprimento dos acordos coletivos e da legislação trabalhista, em especial quanto à extensão da jornada e suas pausas, e estabelecer um monitoramento epidemiológico da saúde física e mental dos profissionais da categoria. Quando mais não fosse, pela importância do transporte coletivo para o bem-estar de toda a comunidade.

\section{NOTAS}

Nossos agradecimentos à Fundacentro, que disponibilizou as bases de dados decorrentes da realização das pesquisas para a análise que constitui objeto deste artigo.

Agradecemos, também, a Paula Montagner, que criou condições para a produção deste artigo e por suas valiosas sugestões e a Edna Yukiko Taira, por sua colaboração no preparo dos dados para a análise estatística.

1. Segundo representantes da Transurb, a velocidade média dos ônibus diminuiu de cerca de 20 a $24 \mathrm{~km} / \mathrm{h}$ para $12 \mathrm{~km} / \mathrm{h}$ entre o início dos anos 90 e 2000.

2. O IMC - Índice de Massa Corporal - é obtido dividindo-se o peso pelo quadrado da altura do indivíduo. São consideradas obesas e préobesas as pessoas com IMC maior ou igual a 25 .

3. As varizes foram agrupadas com as dores osteomusculares porque usualmente quem tem varizes também sente dores nas pernas.

\section{REFERÊNCIAS BIBLIOGRÁFICAS}

BELLUSCI, S.M.; FISCHER, F.M. Envelhecimento funcional e condições de trabalho em servidores forenses. Revista de Saúde Pública, São Paulo, Faculdade de Saúde Pública, v.33, n.6, p.602609, jun. 1999.

BENYAMINI, Y.; LEVENTHAL, E.A.; LEVENTHAL, H. Gender differences in processing information for making self-assessments of health. Psychosomatic Medicine, Philadelphia, Lippincott Williams \& Wilkins, v.62, n.3, p.354-364, May/June 2000.

BOLTANSKI, L. As classes sociais e o corpo. 3. ed. Rio de Janeiro: Graal, 1989.

CANÇADO, V. et al. Capacidade gerencial das empresas de ônibus frente ao órgão gestor em Belo Horizonte. In: BRASILEIRO, A.; HENRY, E. et al. (Org.). Viação ilimitada: ônibus das cidades brasileiras. São Paulo: Cultura Editores Associados, 1999. p.283-314.

CORDEIRO, R. et al. Associação da pressão arterial diastólica com o tempo acumulado de trabalho entre motoristas e cobradores. Revista de Saúde Pública, São Paulo, Faculdade de Saúde Pública, v.27, p.363-372, 1993. 
FACULDADE DE MEDICINA DA USP, FUNDACENTRO E SINDICATO DOS TRABALHADORES NOS TRANSPORTES DE SÃO PAULO. Estudo das condições de saúde e trabalho dos motoristas e cobradores urbanos da cidade de São Paulo. São Paulo, 1990. Mimeografado. [Primeiro relatório de pesquisa].

FERRARO, K.F.; YA-PING, S. Physician-evaluated and self-reported morbidity for predicting disability. American Journal of Public Health, Washington, American Public Health Association (APHA), v.90, n.1, p.103-108, Jan. 2000.

FERREIRA, M.P.; WATANABE, M.I. Razões de risco e probabilidades de acidentes para o trabalhador na Grande São Paulo. Confest, Anais... IV Conferência Nacional de Estatística. Rio de Janeiro: IBGE, 1996. (Tomo II, A sociedade).

FISCHER, F.M. Condições de trabalho e de vida em trabalhadores de setor petroquímico. 1990. Tese (Livre-Docência) - Faculdade de Saúde Pública da USP, São Paulo, 1990.

FISCHER, F.M. et al. Unveiling factors that contribute to funcional aging among health care shiftworkers in São Paulo, Brazil. Experimental Aging Research, London, Taylor \& Francis, v.28, n.1, p.73-86, Jan. 2002.

HENRY, E; ZIONI, S. Ônibus na metrópole, articulações entre iniciativa privada e intervenção pública em São Paulo. In: BRASILEIRO, A.; HENRY, E. et al. (Org.). Viação ilimitada: ônibus das cidades brasileiras. São Paulo: Cultura Editores Associados, 1999. p.119-186.

ILMARINEN, J. Ageing workers in the European Union: status and promotion of work ability, employability and employment. Helsinski: Finnish Institute of Occupational Health/Ministry of Social Affairs/Ministry of Labour, 1999.
LAURELL, A.C.; NORIEGA, M. Processo de produção e saúde. Trabalho e desgaste operário. São Paulo: Hucitec, 1989.

RAJARATNAM, S.M.W.; ARENDT, J. Health in a 24-h society. London: The Lancet. New York: Elsevier Science, v.358, p.9991.005, Sep. 222001.

SIQUEIRA, M.M. de. O papel da regulamentação na gestão pública: o exemplo do transporte coletivo por ônibus. Revista de Administração Pública, Rio de Janeiro, v.31, n.1, p.17-29, jan./fev. 1996.

SMITH, M.J.; COLLIGAN, M.J. e TASTO, D.I. Behavior, research, methods, instruments and computers. Austin (Texas): Psychosomatic Society, v.11, p.9-13, 1979.

SPSS. Statistical Packed Social Sciencie - v.8.0. Regressão Logística (Logistic Regression). USA, 1997.

Leticia B. Costa: Demógrafa, Consultora da Fundação Seade (leticia@seade.gov.br).

Mitti Ayako Hara Koyama: Estatística, Analista da Fundação Seade.

Elaine Garcia Minuci: Estatística, Analista da Fundação Seade.

Frida Marina Fischer: Bióloga, Professora do Departamento de Saúde Ambiental da Faculdade de Saúde Pública da USP (fmfischer@usp.br). 